\title{
THE APRIL MEETING IN NEW MEXICO
}

The six hundredth meeting of the American Mathematical Society was held on Friday and Saturday, April 26-27, 1963 at New Mexico State University, University Park, New Mexico. There were 114 registrants at this meeting, 66 of whom were members of the Society.

By invitation of the Committee to Select Hour Speakers for Far Western Sectional Meetings, there was an address by Professor Robert Steinberg of the University of California, Los Angeles on Presentations and representations of simple groups. Professor Steinberg was introduced by Professor R. B. Crouch.

There were three sessions for contributed papers with Professors E. D. Nering, R. J. Nunke, and E. O. Thorp presiding.

R. S. PIERCE

Associate Secretary 